\title{
Perancangan Sistem Personal Financial Planner Kombinasi Api Firebase Cloud Messaging Berbasis Android
}

\author{
Iryanto Chandra ${ }^{1}$, Yohanes Eka Wibawa ${ }^{2}$ \\ ${ }^{1}$ Fakultas Adab dan Ilmu Budaya, Program Studi Ilmu Perpustakaan \\ Universitas Islam Negeri Sunan Kalijaga Yogyakarta \\ ${ }^{2}$ School of Engineering and Technology, Informatics Engineering \\ Tanri Abeng University - Jakarta Selatan \\ Iryanto.chandra@uin-suka.ac.id
}

\begin{abstract}
Abstrak
Perencanaan keuangan sangatlah penting dalam mendukung realisasi keinginan. Tujuan dari perencanaan keuangan yaitu pengeluaran keuangan tidak lebih besar dari pendapatan sehingga dalam prosesnya membutuhkan cara untuk menjadi pribadi yang lebih sejahtera dengan mengontrol keuangannya dengan bijak dan cermat. Generasi muda saat ini masih banyak yang belum dapat merencanakan dan mengendalikan penggunaan uang untuk pencapaian tujuannya. Melakukan pengendalian dan pencatatan akan biaya pengeluaran sangat sulit karena hasil dari perencanaan keuangan tidak dapat diketahui langsung dan kurang akan informasi perbandingan harga barang. Adanya perancangan sistem keuangan yang dapat dibawa dimana saja akan mempermudah mencatat biaya pengeluaran maupun biaya pemasukan sehari-harinya serta dapat mensimulasikan perencanaan keuangan. Memanfaatkan teknologi API Firebase Cloud Messaging (FCM) untuk memberi informasi barang yang termurah dari beberapa barang keperluan, selanjutnya melakukan perencanaan keuangan dan di implementasikan pada perangkat perangkat pintar Android.
\end{abstract}

\section{Kata kunci: Firebase Cloud Messaging, Perencana Keuangan Pribadi, Simulasi Keuangan, Aplikasi Android}

\begin{abstract}
Financial planning is essential in supporting the realization of desires. The purpose of financial planning is that financial expenditures are not greater than income. The process requires a way to become a more prosperous person by controlling his finances wisely and carefully. Unfortunately, many young people today have not been able to plan and control money to achieve their goals. Controlling and recording expenditure costs is very difficult because financial planning results cannot be known directly, and there is less information on comparing prices of goods. A financial system design that can be carried anywhere will make it easier to record daily expenses and income costs and simulate financial planning - utilizing Firebase Cloud Messaging (FCM) API technology to provide information on the cheapest product from stores and with methods for financial planning and implemented on Android smart devices.
\end{abstract}

Keywords: Firebase Cloud Messaging, Personal Finacial Planner, Financial Simulation Android Application.

\section{PENDAHULUAN}

Data transaksi keuangan sering di jadikan suatu pedoman akan simulasi dari kondisi keuangan. Transaksi debit maupun kredit serta investasi memberikan suatu 
gambaran akan alur cashflow yang dilakukan seseorang.

Financial Planning adalah suatu cara untuk mengatur pengeluaran dan pemasukan dan melakukan perencanaan keuangan agar terhindar dari permasalahan terkait ketimpangan cashflow. Hal ini sangatlah penting untuk mengatur alur keuangan untuk menjadi lebih baik, seperti menekan pengeluaran dan meningkatkan pemasukan, serta dengan perencanaan yang baik agar kondisional dan masalah yang ditimbulkan dapat diminimalisir.

Agar dapat memberikan kemudahan perencanaan dan simulasi keuangan di butuhkan sebuah sistem terintegrasi yang dapat di gunakan untuk mencatat perencanaan keuangan secara realtime agar dapat membantu mempercepat mewujudkan rencana tersebut. Dilakukan pengembangan sistem dengan API Firebase Cloud Messaging (FCM) sebagai sarana mendapatkan data produk terhemat yang sesuai dengan perencanaan pembelian.

Penulis melakukan penelitian akan rancangan sistem berbasis mobile Android tentang aplikasi pencatatan dan perencanaan keuangan pribadi dimana dengan adanya aplikasi tersebut dapat mempermudah pengelolaan keuangan pribadi dan Perencanaan akan tujuan pengeluaran yang terukur.

\section{Rumusan Masalah}

Beberapa rumusan masalah dalam penelitian ini meliputi:

1. Bagaimana memberikan kemudahan informasi kondisi keuangan, catatan keuangan yang dapat di akses dimana saja?

2. Bagaimana memberikan simulasi dan rekomendasi capaian perencanaan keuangan masa depan dan beberapa tujuan pengeluaran yang terukur dan bisa diakses secara real time?

\section{Tujuan Penelitian}

Tujuan yang ingin dicapai dalam penelitian aplikasi Personal Financial Planner ini adalah

1. Memudahkan pengguna aplikasi untuk melakukan pengelolaan keuangan dengan pencatatan yang rapih antara Pemasukan, Pengeluaran dan Perencanaan. Serta memberikan simulasi akan harga barang dan tujuan pengeluaran yang terukur.

2. Memudahkan pengelolaan keuangan yang udah di pahami dan akurat untuk pembukuan transaksi keuangan pengguna.

\section{Manfaat Penelitian}

Manfaat akan penelitian yang dibangun dengan mengembangkan sistem Personal Financial Planner dengan kombinasi API FCM adalah Pengguna dapat melakukan akses dimana pun dan kapan pun dengan data yang realtime untuk memberikan informasi terkini keuangan pengguna, data transaksi, dan simulasi pengeluaran dan perbandingan data produk untuk tujuan yang diingkan.

\section{Tinjauan Pustaka}

Dalam Penelitian sebelumnya akan topik dan pembahasan Financial Planning, dikembangkan beberapa fitur simulasi dan pengamatan akan catatan keuangan yang dilakukan oleh Pengguna. Penulis merangkum akan beberapa Penelitian sebelumnya sebagai berikut:

Tabel 1. Daftar Tinjauan Pustaka 


\begin{tabular}{|c|c|c|}
\hline Author / Title & Feature & Deficiency \\
\hline $\begin{array}{l}\text { Sistem Pencatatan } \\
\text { Dan Pengolahan } \\
\text { Keuangan Pada } \\
\text { Aplikasi Manajemen } \\
\text { Keuangan E-Dompet } \\
\text { Berbasis Android } \\
\text { (Juhardi\&Khairullah } \\
\text { 2019) [1] }\end{array}$ & $\begin{array}{l}\text { Aplikasi sudah } \\
\text { memberikan } \\
\text { banyak kategori } \\
\text { transaksi } \\
\text { sehingga } \\
\text { memudahkan } \\
\text { pengguna untuk } \\
\text { memilih } \\
\text { transkasi. }\end{array}$ & $\begin{array}{l}\text { Laporan } \\
\text { Keuangan } \\
\text { Masih } \\
\text { Dilakukan } \\
\text { Secara } \\
\text { Manual, } \\
\text { Menghitungnya } \\
\text { Secara Manual. }\end{array}$ \\
\hline $\begin{array}{l}\text { Aplikasi Manajemen } \\
\text { Keuangan Pribadi } \\
\text { (Angsa) Berbasis } \\
\text { Android (Ade et } \\
\text { al.,2019) [2] }\end{array}$ & $\begin{array}{l}\text { Aplikasi dapat } \\
\text { mencatat } \\
\text { tentang } \\
\text { KPR (Kredit } \\
\text { Kepemilikan } \\
\text { Rumah) } \\
\text { Pengguna. }\end{array}$ & $\begin{array}{l}\text { Pengaturan } \\
\text { keuangan secara } \\
\text { manual kurang } \\
\text { efisien karena } \\
\text { tidak dapat } \\
\text { dilakukan setiap } \\
\text { saat. }\end{array}$ \\
\hline $\begin{array}{l}\text { Pembuatan Aplikasi } \\
\text { Management } \\
\text { Keuangan Pribadi } \\
\text { Berbasis Android } \\
\text { (Syarwan et al., } \\
\text { 2018) [3] }\end{array}$ & $\begin{array}{l}\text { Aplikasi dapat } \\
\text { memberikan } \\
\text { infomrasi } \\
\text { tentang } \\
\text { pengeluaran } \\
\text { yang } \\
\text { rutin di } \\
\text { keluarkan } \\
\text { oleh pengguna. }\end{array}$ & $\begin{array}{l}\text { Pencatatan } \\
\text { manual dirasa } \\
\text { menyulitkan } \\
\text { karena catatan } \\
\text { bisa hilang atau } \\
\text { bisa lupa untuk } \\
\text { dicatat. }\end{array}$ \\
\hline $\begin{array}{l}\text { Pengembangan } \\
\text { Aplikasi Mobile } \\
\text { Manajemen } \\
\text { Keuangan Dengan } \\
\text { Metode Scrum (Arka } \\
\text { etal., 2019) [4] }\end{array}$ & $\begin{array}{l}\text { Aplikasi dapat } \\
\text { memberikan } \\
\text { notifikasi ketika } \\
\text { pengeluaran } \\
\text { sudah } \\
\text { mendekati nilai } \\
\text { minimum batas } \\
\text { harian yang } \\
\text { telah } \\
\text { ditentukan. }\end{array}$ & $\begin{array}{l}\text { Aplikasi tidak } \\
\text { dapat } \\
\text { memberikan } \\
\text { simulasi } \\
\text { perhitungan } \\
\text { perencanaan } \\
\text { keuangan } \\
\text { pengguna dan } \\
\text { tidak dapat } \\
\text { export } \\
\text { data laporan. }\end{array}$ \\
\hline
\end{tabular}

\section{LANDASAN TEORI}

\section{Manajemen Keuangan}

Manajemen keuangan pribadi adalah suatu proses mengatur keuangan individu untuk mencapai kepuasan ekonomi pribadi. Proses manajemen ini dapat membantu individu dalam mengontrol kondisi keuangannya. Setiap individu memiliki keadaan ekonomi (keuangan) yang berbeda sehingga dibutuhkan pengelolaan dalam merencanakan keuangan untuk memenuhi kebutuhan dan tujuan tertentu [5].

\section{Pengeluaran}

Pengeluaran yaitu kegiatan mengeluarkan uang untuk tujuan tertentu. Setiap individu mempunyai kebutuhan yang berbeda, sehingga pengelolaan uang antara individu yang satu dengan individu yang lain juga berbeda. Pengeluaran dapat di bagi menjadi beberapa kategori, antara lain:

1. Pengeluaran Harian

Pengeluaran harian yaitu kegiatan mengeluarkan uang setiap hari. Contoh pengeluaran harian yaitu makan, ongkos naik angkutan umum, dan lainlain.

2. Pengeluaran Berkala

Pengeluaran berkala yaitu kegiatan mengeluarkan uang sesuai jangka waktu kebutuhan. Contoh pengeluaran berkala yaitu biaya isi pulsa, biaya isi bensin, belanja, dan lain-lain.

3. Pengeluaran Bulanan

Pengeluaran bulanan yaitu kegiatan mengeluarkan uang yang rutin dilakukan setiap satu bulan sekali. Contoh pengeluaran bulanan yaitu bayar kost, bayar listrik, bayar air, bayar cicilan kredit sepeda motor dan lain-lain.

4. Pengeluaran tak terduga

Pengeluaran tak terduga yaitu kegiatan mengeluarkan uang untuk keperluan yang tak terduga. Contoh tak terduga yaitu biaya Kesehatan. [6].

\section{Entity Relationship Diagram (ERD)}

Data model adalah cara formal untuk menggambarkan data yangdigunakan dan diciptakan dalam suatu sistem bisnis. [11]. Pemodelan data dibagi menjadi dua, yaitu model data logis (logical data model) dan model data fisik (physical data model). Model data logis menunjukkan pengaturan 
data tanpa mengindikasikan bagaimana data tersebut disimpan, dibuat, dan dimanipulasi. Model data fisik menunjukkan bagaimana data akan disimpan sebenarnya dalam database.

\section{Use Case Diagram}

Use Case Diagram adalah pemodelan untuk menggambarkan behavior / kelakuan sistem yang akan dibuat. Use case diagrammenggambarkan sebuah interaksi antara satu atau lebih aktor dengan sistem yang akan dibuat. Secara sederhana, diagram use case digunakan untuk memahami fungsi apa saja yang ada di dalam sebuah sistem dan siapa saja yang dapat menggunakan fungsi-fungsi tersebut.[9]

\section{Firebase API / Firebase Cloud Messaging}

Firebase adalah suatu layanan dari Google yang digunakan untuk mempermudah para pengembang aplikasi dalam mengembangkan aplikasi. Salah satu fitur yang menarik dari Firebase yaitu Firebase Realtime Database.[10]

Implementasi Firebase Cloud Messaging melingkupi dua bagian utama untuk mengirim dan menerima pesan yaitu server aplikasi yang digunakan untuk membuat dan mengirim pesan serta yang menerima pesan seperti android.

Firebase cloud messaging dapat mengirim pesan berupa pesan notifikasi dan juga pesan data. Pesan notifikasi dipakai bila FCM menangani tampilan notifikasi atas nama aplikasi pengguna. Dan pesan data digunakan jika ingin memproses pesan pada aplikasi klien [10]
Agile software development adalah metode yang meringankan beban/bobot sekaligus mempercepat proses pengembangan software. Pada metode Agile, terjadi iterasi pendek yang diikuti pengiriman produk yang mengalami peningkatan secara sering (Frequent). Agile juga melakukan penekanan komunikasi langsung dan berkala untuk tim pengembangan, bahkan pelanggan (Client) juga terlibat secara aktif dalam siklus proses pengembangan.[5]

Dengan menggunakan scrum akan mempermudah dalam pengerjaan, karena dapat melakukan pengembangan saat pembangunan perangkat lunak sedang berlangsung. Scrum adalah kerangka kerja di mana orang dapat mengatasi masalah adaptif yang kompleks, tetapi juga secara produktif dan kreatif memberikan produk dengan nilai setinggi mungkin.

Dalam melakukan penelitian ini penulis menggunakan metode perancangan scrum untuk mengembangkan dan mempertahankan produk yang kompleks. Pengambilan kesimpulan akan dilakukan setelah semua iterasi dari Scrum Sprint telah selesai dilaksanakan. Kesimpulan diambil berdasarkan hasil analisis dan pengujian sistem yang telah dibuat.

\section{METODE PENELITIAN}

Perancangan Sistem yang dibangun adalah dengan mengembangkan Sistem berbasis mobile android dengan langkah pengembangan perangkat lunak secara Agile Scrum sebagai berikut :

\section{Agile - Scrum}




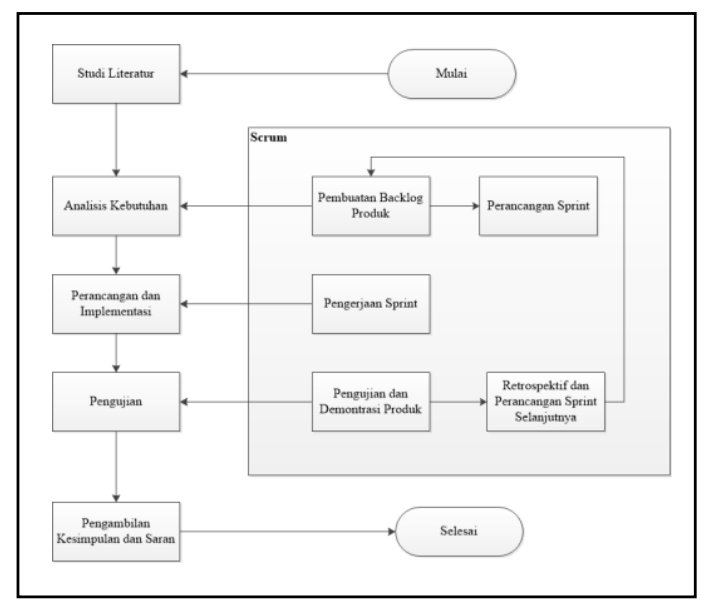

Gambar 1. Alur Penelitian

ANALISIS DAN PERANCANGAN

A. Deskripsi Umum sistem

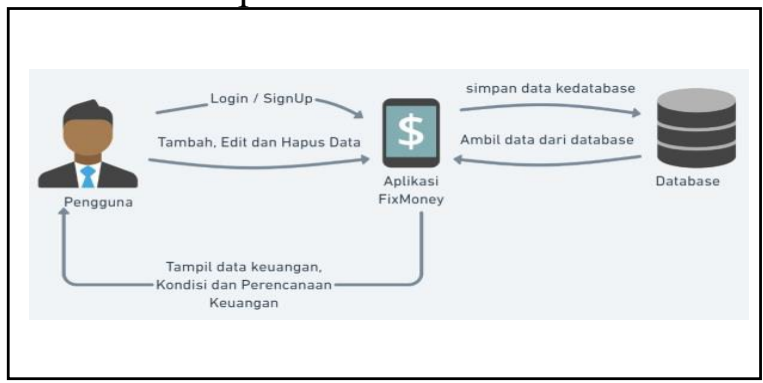

Gambar 2. Deskripsi kinerja sistem

Pada gambar ditunjukan terdapat alur kerja dari sistem yang dikembangkan yang terdiri atas pengguna, aplikasi dan database yang merupakan satu kesatuan sistem yang akan terhubung dengan API Firebase yang sekaligus sebagai DBMS. Pengguna dapat melakukan akses untuk lebih dari satu perangkat Android. [7]

\section{B. Entity Relationship Diagram (ERD)}

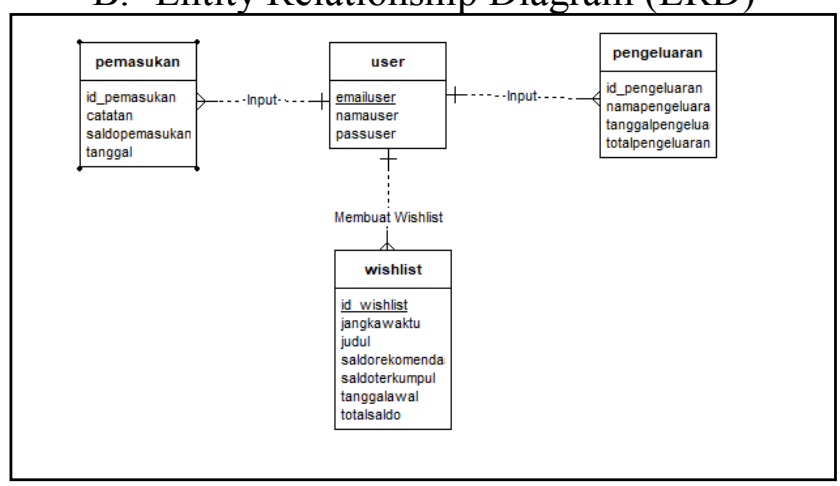

Gambar 3. Entity Relationship Diagram (ERD) sistem
Pada gambar ditunjukan terdapat relasi antar table yang digunakan dalam perancangan sistem ini yang melibatkan beberapa tabel yang terkait satu sama lain.

C. Use Case Diagram Sistem

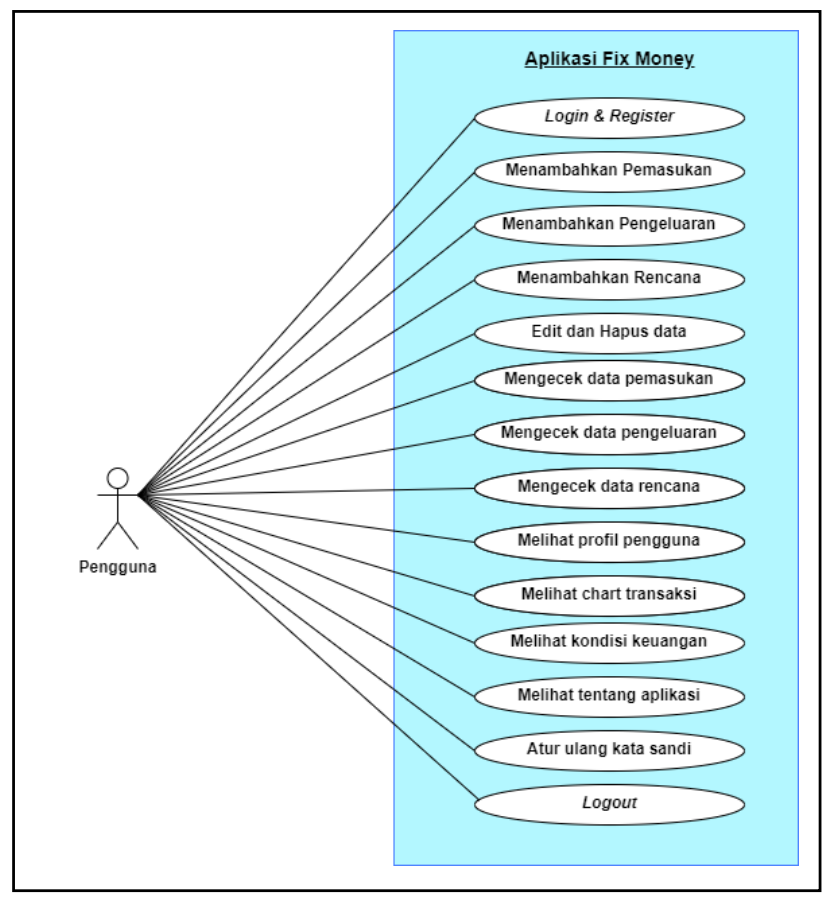

Gambar 4. Use Case Rancangan Sistem

Pada gambar ditunjukan terdapat relasi Use Case yang menjadi rancangan sistem dengan beberapa uses case yang di sesuaikan dengan pengembangan sistem yang saat ini berjalan.

\section{IMPLEMENTASI DAN PEMBAHASAN}

Perancangan sistem ini di kembangan dengan bahasa pemrograman native Android menggunakan API Firebase Realtime Database dengan kombinasi Implementasi Firebase Cloud Messaging melingkupi dua bagian utama untuk mengirim dan menerima pesan yaitu server aplikasi yang digunakan untuk membuat dan mengirim pesan serta yang menerima pesan notifikasi bila FCM menangani 
tampilan notifikasi atas nama aplikasi pengguna.

Dalam melakukan implementasi tersebut penulis mengacu pada user interface yang telah dirancang dan di terapkan kedalam java code dan XML. Untuk alur fungsionalitas mengacu kepada UML sedangkan untuk alur database yang ada pada sistem penulis mengacu kepada ERD, untuk melakukan implementasi istem ini di jalankan pada perangkat mobile dengan platform Android Minimal versi 6.0 Marshmallow.

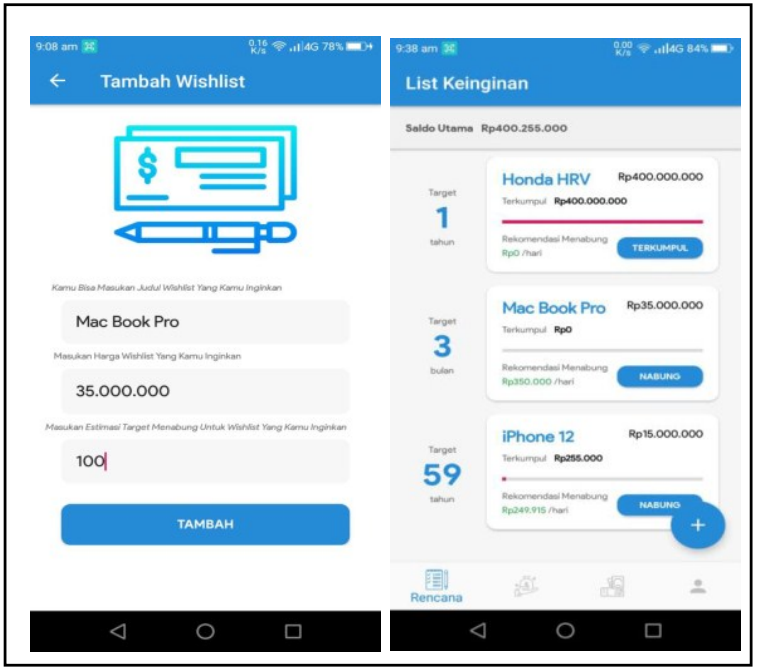

Gambar 5. User Interface Perencanaan Tujuan

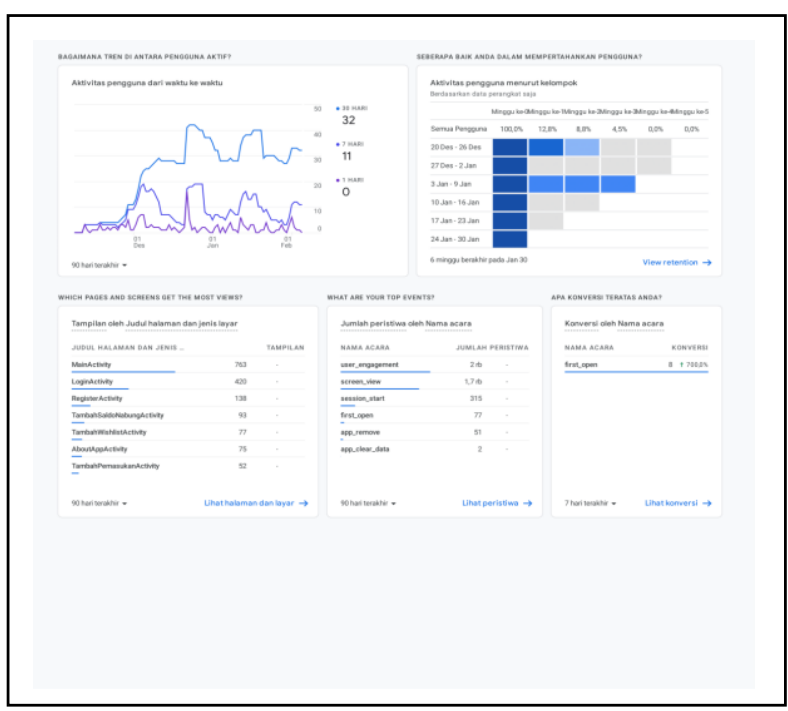

Gambar 6. Console Firebase
Pemanfaatan teknologi Firebase API Firebase Cloud Messaging yang ada pada console telah berhasil diterapkan dalam Sistem.

Pengguna sistem dapat melihat semua data rencana yang telah di input seperti Saldo Utama adalah nilai Total akumulasi dari saldo rencana yang telah terkumpul, Target hari adalah estimasi lama menabung, progres bar warna merah akan bergerak selama pengguna menabung sampai saldo terkumpul, rekomendasi Menabung adalah nilai yang di rekomendasikan oleh aplikasi untuk menabung setiap hari, Button nabung adalah untuk menambah tabungan, button ini akan berubah nama menjadi "terkumpul" apabila nilai target saldo telah terkumpul.

Penggunaan firebase realtime database. yaitu salah satu proses yang di lakukan untuk memudahkan memberikan informasi data pengguna pada sistem.

Realtime Database ini di manfaatkan pada semua activity yang memerlukan penyimpanan data seperti data pengguna, data rencana keuangan, data pengeluaran dan data tambah pemasukan.

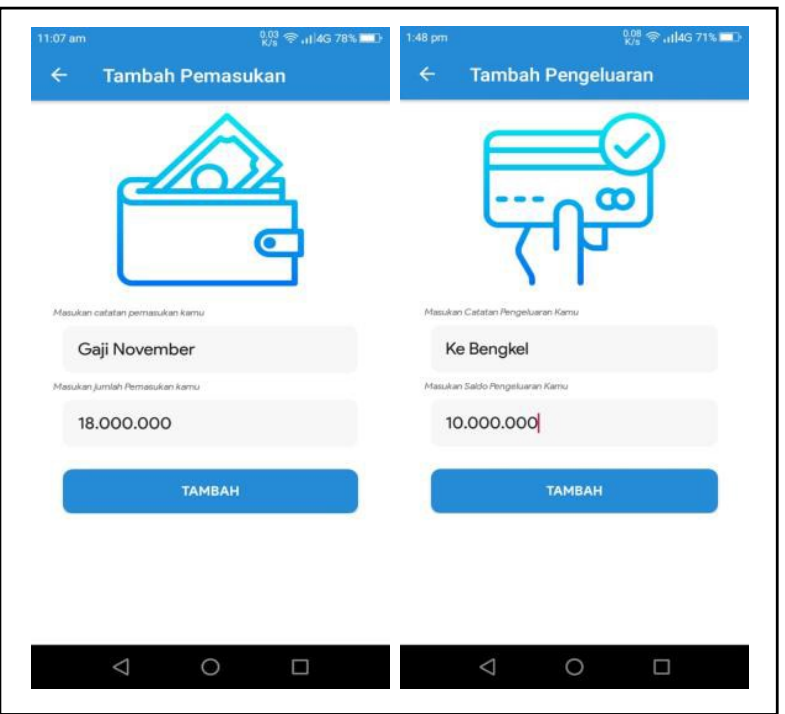


Gambar 7. UI Tambah Pemasukan dan pengeluaran

Pada bagian menu tambah pemasukan dan tambah pengeluaran semua kolom harus terisi dengan benar seperti memasukan catatan lalu memasukan saldo, kemudian tekan button tambah dan aplikasi akan memproses penyimpanan, kemudian data akan tampil di menu pengeluaran. Apabila ada kolom yang tidak terisi $n$ muncul pesan "Semua Kolom Harus Terisi”.

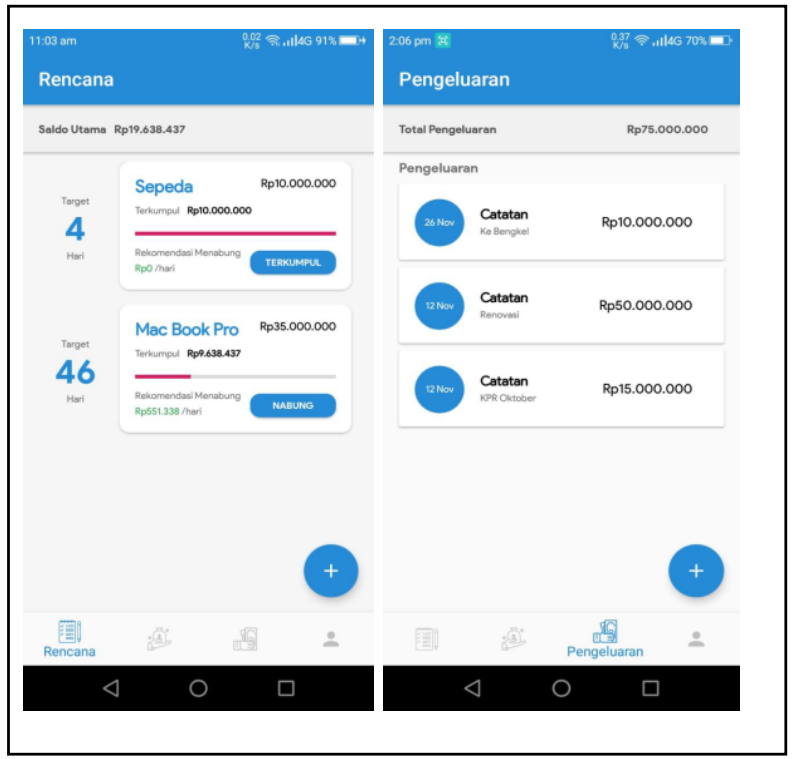

Gambar 8. UI Rencana dan pengeluaran

Padabagian menu ini juga terdapat informasi tentang kondisi keuangan pengguna apabila pemasukan lebih banyak dari pengeluaran maka kondisi keuangan baik demikian pula dalam kondisi yang sebaliknya.

\section{KESIMPULAN}

Berdasarkan seluruh tahapan penelitian yang di lakukan maka didapat sebuah rancangan sistem Personal Financial Planner untuk pencatatan dan perencanaan keuangan akan mempermudah mencatat biaya pengeluaran maupun biaya pemasukan sehari-harinya serta dapat mensimulasikan perencanaan keuangan. Selanjutnya sistem dapat memberikan rekomendasi perhitungan perencanaan keuangan, agar pengguna lebih giat lagi untuk menabung.

Setelah melakukan pengumpulan data, perancangan sistem sampai ke penulisan program dan terakhir dengan melakukan pengujiann menggunakan metode black box testing yang dimana perangkat lunak ini sudah berjalan sesuai dengan yang diharapkan, sehingga perangkat lunak ini berhasil dibuat dan sudah di publish di Google Playstore agar dapat digunakan oleh masyarakat.

\section{SARAN}

Penelitian selanjutnya diharapkan untuk mengkaji lebih banyak sumber maupun referensi yang terkait dengan pembangunan aplikasi pencatatan keuangan agar hasil penelitianya dapat lebih baik dan lebih lengkap lagi.

Penelitian selanjutnya diharapkan dapat membuat dan mengintegrasikan dengan web-based sehingga lebih memudahkan lagi bagi pengguna untuk memonitoring data keuanganya.

\section{DAFTAR PUSTAKA}

[1] Juhardi, U., \& Khairullah, K. (2019). Sistem Pencatatan dan Pengolahan Keuangan Pada Aplikasi Manajemen Keuangan E-Dompet Berbasis Android. Journal of Technopreneurship and Information System (JTIS), 2(1), 24-29. https://doi.org/10.36085/jtis.v2i1.215

[2] Ade, D., Capah, H., \& Buana, U. M. (2019). Aplikasi manajemen keuangan pribadi (angsa) berbasis android. 2(5), 174-182. 
[3] Syarwan, B. A., Purba, K. R., \& Setiawan, A. (2018). Pembuatan Aplikasi Management Keuangan Pribadi Berbasis Android. Jurnal Infra Petra, 3-6.

[4] Putra, I. G. N. A. C. (2016). Perancangan Aplikasi Keuangan Mahasiswa Berbasis Mobile. Jurnal Ilmiah ILMU KOMPUTER Universitas Udayana. ISSN 1979 5661, IX(2), 9-14.

[5] Arka. (2019), Pengembangan Aplikasi Mobile Manajemen Keuangan dengan Metode Scrum (Studi Kasus Mahasiswa FILKOM UB)

[6] Susanto, A., Noertjahyana, A., \& Setiawan, A. (2016). Aplikasi Pengelola Keuangan Pribadi Berbasis Android. Jurnal Infra, 031, 2-5.

[7] Sukur, M., Purwaningtyas, P., \& Al Amin, I. H. (2017). Rancang Bangun Aplikasi Sistem Perencanaan Dan Pencatatan Anggaran Biaya Keluarga Menggunakan Metode Budgeting. Dinamik, 22(1), 30-38. https://doi.org/10.35315/dinamik.v22 i1.7103

[8] Fowler, M. (2004). UML distilled: a brief guide to the standard object modeling language. Addison-Wesley Professional.

[9] R. S. Pressman, Software Engineering: a Practitioner approach. New York: McGraw Hill, 2010.

[10] Yogiswara and D. R. Astriyanto, "Penerapan Web Service Dan Firebase Notification Pada Pengembangan Aplikasi Gerakan Nasi Bungkus Jember Berbasis Android," Inform. Polinema, vol. 4 No.2, pp. 161-167, 2018.Fowler, M. (2004). UML distilled: a brief guide to the standard object modeling language. Addison-Wesley Professional.
[11] GlobalStats, S. (2020). Mobile Operating System Market Share Indonesia.https://gs.statcounter.com/ os-marketshare/mobile/Indonesia

[12] A. N. Yushnita, "Pentingnya Literasi Keuangan Bagi Pengelolaan Keuangan Pribadi," Nominal, vol. VI NOMOR 1, pp. 11-26, 2017. 